\title{
Commensal-Epithelial Signaling Mediated via Formyl Peptide Receptors
}

Christy C. Wentworth, Rheinallt M. Jones, Young Man Kwon, Asma Nusrat, and Andrew S. Neish

From the Epithelial Pathobiology Unit, Department of Pathology and Laboratory Medicine, Emory University School of Medicine, Atlanta, Georgia

Commensal bacteria and/or their products engender beneficial effects to the mammalian gut, including stimulating physiological cellular turnover and enhancing wound healing, without activating overt inflammation. In the present study, we observed commensal bacteriamediated activation of the noninflammatory extracellular signal-regulated kinase[ERK]/mitogen-activated protein kinase and Akt signaling pathways in gut epithelial cells and delineated a mechanism for this bacterially activated signaling. All tested strains of commensal bacteria induced ERK phosphorylation without stimulating pro-inflammatory phospho-IkB or pro-apoptotic phospho-c-Jun $\mathrm{NH}_{2}$-terminal kinase, with Lactobacillus species being most potent. This pattern of signaling activation was recapitulated using the peptide $N$-formyl-MetLeu-Phe, a bacterial product known to stimulate signaling events in mammalian phagocytes. Sensing of $\boldsymbol{N}$-formyl-Met-Leu-Phe by gut epithelial cells occurs via recently characterized formyl peptide receptors located in the plasma membrane. Both commensal bacteria and $\boldsymbol{N}$-formyl-Met-Leu-Phe application to the apical surface of polarized gut epithelial cells resulted in specific formyl peptide receptor activation. In addition, pretreatment of model epithelia and murine colon with Boc2 (a specific peptide antagonist) or pertussis toxin (a $\mathrm{G}_{\mathrm{i}}$-protein inhibitor) abolished commensalmediated ERK phosphorylation. Taken together, these data show that commensal bacteria specifically activate the ERK/mitogen-activated protein kinase pathway in an formyl peptide receptor-dependent manner, delineating a mechanism by which commensal bacteria contribute to cellular signaling in gut epithelia. (Am J Pathol 2010, 177:2782-2790; DOI: 10.2353/ajpath.2010.100529)

Commensal microbe-host interactions in the human gut have evolved over millennia. The diverse community of microbes that inhabit the human gastrointestinal tract are comprised of 10 to 100 trillion organisms representing about 500 genera of bacteria, grouped into two broad taxa, the Bacteroidetes and Firmicutes. ${ }^{1,2}$ The microbiota thrives in a thermostable nutrient-rich environment and provides beneficial functions to the host including energy extraction of otherwise indigestible complex carbohydrates, vitamin and micronutrient syntheses, stimulation of immune development/function, and competitive exclusion of pathogens. ${ }^{3,4}$ Additionally, studies with germ-free mice have revealed that the small intestinal crypts exhibit a slower turnover of the epithelial cells, with crypt-to-villus transit time double in germ-free animals. ${ }^{5}$ Regenerative responses to colonic injury are markedly attenuated in germ-free animals, ${ }^{6}$ indicating a role of the microbiota in induction of epithelial proliferation and response to injury.

Recognition of this mutually beneficial relationship has prompted increasing interest in potential therapeutic benefits of supplementing the normal flora with exogenous viable bacteria. This approach, termed probiotics, has been reported to modulate inflammation, augment barrier function and stimulate reparative responses in vitro, and has shown promise as therapy in inflammatory and developmental disorders of the intestinal tract. ${ }^{7}$ However, in other cases, the quantitative and/or qualitative abnormalities of the microbiota may be sufficient to provoke intestinal inflammation as seen in inflammatory bowel disease [which includes Ulcerative colitis and Crohn's disease] and contribute to other systemic immune, allergic, metabolic, and infectious disorders. ${ }^{8}$ Thus, there is increasing evidence that the microbiota profoundly influences intestinal- and systemic-homeostasis and health. However, little is known of how the host perceives nonpathogenic bacteria, or how microbiota mechanistically influences gut biology.

The microbiota is separated from the host systemic compartment by only a single layer of epithelial cells,

Supported by the NIH grant R01DK071604, DK089763, and Al064462. R.M.J. is supported by K01DK081481.

Accepted for publication July 29, 2010

Supplemental material for this article can be found on http://ajp. amjpathol.org.

Address reprint requests to Andrew S. Neish, M.D., Department of Pathology, Emory University School of Medicine, Room 105F, Whitehead Bldg., 615 Michael Street, Atlanta GA, 30322, E-mail: aneish@emory.edu. 
which are able to respond to and manage threats from bacterial pathogens-and by extrapolation, respond to and manage commensals. ${ }^{9,10}$ Transmembrane and intracytoplasmic receptors, such as the now well characterized Toll-like receptors (TLRs) and related Nod proteins, are designated "pattern recognition receptors" or PRRs, that recognize and bind to conserved structural motifs characteristic of a wide range of microbes, which are termed MAMPs, or "microbe associated molecular patterns." A different class of candidate pattern recognition receptors are the formyl peptide receptors (FPRs), which are seven transmembrane receptors originally described on neutrophils and macrophages. ${ }^{11-13}$ The best characterized FPR ligands are formyl peptides, prokaryotic translation products modified with $\mathrm{N}$-formyl-methionine, a bacterial specific amino acid. Upon ligand binding in phagocytes, FPRs undergo a conformational change that allows recruitment of pertussis toxin (PTx) sensitive $G$ proteins of the $G_{i}$ family. This signaling eventuates in 1) changes in actin dynamics and initiation of chemotaxis, 2) transcriptional up-regulation of inflammatory effectors and cytokines, and 3) the activation of NADPH enzymes and ROS generation (respiratory burst). Thus, the FPRs are key PRRs that control the biological response of professional phagocytes to bacterial ligands. FPRs are represented in humans by the originally characterized FPR1, and the closely related FPR2/ALX. Recently, we demonstrated FPR localization on epithelial cells along the crypt-lumen axis in human mucosal biopsies, ${ }^{14}$ prompting interest that FPRs and related epithelial receptors may mediate physiological responses in the gut. Interestingly, FPR2/ALX signals in a non-phlogistic fashion ${ }^{15}$ and may thus be a candidate for commensal mediated homeostatic signaling. Indeed, Annexin 1, a ligand of FPR2/ALX, has been shown to have restitutive effects in wounded gut, ${ }^{16}$ and the anti-microbial bactericidal/permeability-increasing protein is stimulated in the gut by FPR signaling. ${ }^{17}$

Epithelial cellular signaling induced by most PRRs involves the highly conserved mitogen-activated protein kinase (MAPK) and related nuclear factor (NF)- $\kappa$ B systems. ${ }^{18}$ MAPK pathways (p38, c-Jun $\mathrm{NH}_{2}$-terminal kinase [JNK], extracellular signal-regulated kinase $[E R K]$ ) are signaling relays that use three kinase phosphorylation cascades (MAPKKK to MAPKK to MAPK) to transduce a myriad of extracellular stimuli into intracellular signaling events, including initiating gene transcription, stimulating cytoskeletal alterations and other functions. We and others have previously reported that enteric pathogenic bacteria, such as Salmonella, activate MAPK and NF- $\kappa \mathrm{B}$ pathway signaling in polarized cultured epithelial cell monolayers, and also identified TLRs as the likely signaling mediators. ${ }^{19}$ However, in a normal healthy mammalian gut, the enteric commensal bacteria are in intimate contact with the epithelia, yet they do not activate epithelial cell pro-inflammatory or pro-apoptotic signaling pathways above tonic levels. Additionally, expression profiling studies of cultured cells treated with commensal bacteria showed significant induction of a range of epithelial related genes. ${ }^{20}$ In this study, we sought to characterize how commensal bacteria could influence epithelial signaling events. Herein, we show that a spectrum of viable commensal gut bacteria is sensed by FPRs located on enterocyte apical membranes of the intestine in vitro and in vivo. We show that bacterial/epithelial cell contact results in potent FPR and G protein dependent activation of the ERK signaling pathway. These findings describe a novel mechanism of non-pro-inflammatory bacteria-host communication, and define a previously unknown pattern recognition receptor in the mammalian gut.

\section{Materials and Methods}

\section{Reagents}

Flagellin was a generous gift from Dr. Andrew Gewirtz. Recombinant human tumor necrosis factor (TNF)- $\alpha$ and epidermal growth factor (EGF) were purchased from R\&D Systems (Minneapolis, MN), PTx from Calbiochem (Darmstadt, Germany), and FPR antagonist N-tert-butoxycarbonyl-Met-Leu-Phe (Boc2) through MP Biomedicals (Aurora, $\mathrm{OH}$ ).

\section{Cell Culture}

T84 epithelial cells were prepared on $5-\mathrm{cm}^{2}$ permeable filters as described previously ${ }^{21}$ and were used 9 to 14 days after plating and achieving a stable transepithelial resistance of $>1000 \Omega \cdot \mathrm{cm}^{2}$. The intestinal epithelial cell line SK-CO15 were grown and maintained as previously described. ${ }^{16}$ Primary Murine bone marrow derived macrophages (BMMs) were prepared as previously described. ${ }^{22}$ Marrow was extracted from femora and tibia of 8-week-old mice in a BL6 background and cultured in Dulbecco's modified Eagle's medium containing 10\% fetal bovine serum and $100 \mathrm{ng} / \mathrm{ml}$ macrophage-colony stimulating factor from Sigma (St. Louis, MO). Cells were incubated at $37^{\circ} \mathrm{C}$ for 5 days, then medium changed every 2 days until cell were confluent.

\section{Cecal Flora Preparation}

Murine cecal contents were removed and suspended in PBS. Fecal debris was pelleted following centrifugation at $100 \times g$. Supernatant was transferred to a new tube and centrifuged at $10,000 \times g$ to pellet bacterial flora. Supernatant was removed, and pelleted bacteria were diluted in $1 \mathrm{ml} \mathrm{PBS}$.

\section{Bacterial Strains}

Lactobacillus rhamnosus GG (ATCC \#11975), Lactobacillus acidophilus (ATCC \#11975), Lactobacillus casei (ATCC \#11578), Bacteriodes thetaiotaomicron (ATCC \#12290), Streptococcus thermophilus (ATCC \#14485), Salmonella typhimurium (ATCC \#13311), and Escherichia coli (derived from $\mathrm{DH} 5 \alpha$ strain from Invitrogen, Carlsbad, CA) were grown and prepared as previously described. ${ }^{23}$ Unless otherwise noted, all bacteria were used at $5 \times 10^{7}$ colonyforming units (cfu)/ml. 


\section{Cell Wall Preparation}

L. rhamnosus GG was grown to $5 \times 10^{7} \mathrm{cfu} / \mathrm{ml}$. Bacterial cells were disrupted by sonication, centrifuged at $1000 \times g$ to pellet bacterial debris. The resulting supernatant was collected and centrifuged at $30,000 \times g$ to obtain the membrane fraction. The pelleted fraction was then resuspended in initial volume equivalent of Dulbecco's modified Eagle's medium.

\section{Immunoblotting and Immunofluorescence}

Antibodies were obtained as follows: anti $\mid \kappa \mathrm{B}-\alpha$ (Santa Cruz Biotechnology Inc., Santa Cruz, CA), phospho-JNK, phospho-ERK, and phospho-Akt (Cell Signaling, Danvers, MA), $\beta$-actin (Sigma-Aldrich), phosphoserine/threonine (AbCam, Cambridge, MA; 17464-50), fluorescein isothiocyanate-conjugated goat anti-rabbit IgG (Jackson ImmunoResearch, West Grove, PA), and horseradish peroxidase-conjugated donkey anti-rabbit or sheep antimouse secondary antibody (GE Health care, Buckinghamshire, UK). Mouse anti-FPR monoclonal antibody was a generous gift from Dr. Algeris Jesaitis. This antibody is a monoclonal antibody prepared against 305-GQDFRERLI313 peptides present on both human FPR1 and FPR2/ANX and recognizes a $\sim 60-\mathrm{kDa}$ band in transfected Chinese hamster ovary epithelial cells. ${ }^{24}$ Immunoblot and immunofluorescent labeling slips was performed as previously described. ${ }^{25}$ Nuclei were stained with To-Pro-3 iodide (Molecular Probes, Carlsbad, CA). Fluorescent images acquired by laser confocal microscopy through an $\times 63$ objective.

\section{Reporter Gene Assays}

SK-CO15 cells were transiently transfected using Lipofectamine 2000 (Invitrogen Life Technologies) according to manufacturer's instructions. For luciferase reporter assays, cells were transfected with NF- $\kappa \mathrm{B}-$ dependent pNF$\kappa$ B-Luc, ERK-dependent Elk1, or JNK-dependent C-Jun reporter plasmids (Luciferase Trans-Reporting Systems, Stratagene, La Jolla, CA) according to manufacturer's instructions. Following cell treatment, cells were lysed in reporter lysis buffer (Promega, Madison, WI) and activity determined using the Dual Luciferase Reporter Assay System (Promega).

\section{5-Ethynyl-2' Deoxyuridine Incorporation Assay}

SK-CO15 cells were grown to $90 \%$ confluency on glass coverslips. Following experimental treatment for 12 hours, cells were treated with 5-ethynyl-2' deoxyuridine (EdU) according to manufacturer's instructions (Invitrogen Click-iT EdU Imaging 488). Nuclei were stained with To-Pro-3 iodide (Molecular Probes). Fluorescent images acquired by Confocal Microscopy through an $\times 63$ objective. For quantitative analysis, 10 fields of view were randomly selected for each treatment.

\section{Denaturing Immunoprecipitation}

Following experimental treatment, epithelial cells were washed in cold Hank's buffered salt solution, lysed in denaturing $1 \%$ SDS lysis buffer and heated to $95^{\circ} \mathrm{C}$. SDS was then quenched to $0.1 \%$ by adding Triton $\mathrm{X}$ - 100 lysis buffer. DNA was fragmented by passing lysate through a $25 \mathrm{G}$ needle and protein stabilized by incubation on ice. Samples were precleared 1 hour on ice before incubation with $\sim 1 \mu \mathrm{g} / \mathrm{ml}$ FPR1 monoclonal antibody. ${ }^{24}$ FPR1/antibody conjugates were then precipitated using $50 \%$ slurry of IgG coated agarose beads (ThermoScientific, Waltham, MA). Protein was released from the beads by incubation with $2 \times \mathrm{SDS}$ lysis buffer at $95^{\circ} \mathrm{C}$ for 5 minutes. Samples were immunoblotted using an antibody against FPR1 or Rb polyclonal antibody phosphoserine/ threonine (AbCam 17464-50). Densitometric analysis was performed using Scion Image $\beta$.

\section{Mice}

All murine experimental procedures were undertaken according to Emory University guidelines for ethical treatment of animals. Ileal loop analysis of 6- to 8-week-old BL6 (Jackson labs) or MyD88 -/- mice was conducted as previously described. ${ }^{26}$ Briefly, the colon was opened along the mesenteric border, epithelial tissue scraped and collected before administration of PBS, L. rhamnosus GG, or formyl-Met-Leu-Phe tripeptide (fMLF) for up to 7 minutes, lysed in radioimmunoprecipitation assay buffer (100 mg tissue/ml of buffer) and centrifuged at 16,000 r.p.m. for 20 minutes at $4^{\circ} \mathrm{C}$. Protein concentrations of supernatants were determined by protein assay (BioRad, Hercules, CA). For analysis of colonic tissue by intrarectal (i.r.) treatment, 6- to 8-week-old B6 mice were anesthetized before administration of PBS, L. rhamnosus GG, or fMLF for up to 7 minutes. Subjects were euthanized, and tissues removed for analysis. The colon was opened along the mesenteric border, placed in $4 \%$ paraformaldehyde 20 minutes, and subsequent colon whole mount preparation performed as described below. For control experiments, mice were systemically administered $1 \mu \mathrm{g} / \mathrm{ml}$ PTx via i.p. injection for 18 hours before $L$. rhamnosus GG treatment. For fMLF peptidomimetic control, mice were intrarectally administered $100 \mu \mathrm{g} / \mathrm{ml}$ Boc2 through soft catheter 30 minutes before L. rhamnosus GG treatment.

\section{Colon Whole Mount Preparation}

Dissected murine tissues were fixed for 20 minutes in 4\% paraformaldehyde, washed in PBS, permeabilized with $0.1 \%$ Triton X-100 for 5 minutes, and washed again. Samples were blocked in 5\% normal goat serum for 1 hour before incubation with rabbit anti-phospho-ERK (Cell Signaling) for 1 hour at $37^{\circ} \mathrm{C}$ (or o/n at $4^{\circ} \mathrm{C}$ ), and then with fluorescein isothiocyanate-conjugated goat anti-rabbit IgG (Jackson ImmunoResearch). Cellular actin was stained with Alexa Flour Phallodin-633 (Molecular Probes). Tissue was cut into 2-mm to 5-mm small pieces, mounted on slides and visualized by Laser Confocal Microscopy at $\times 63$. 
A

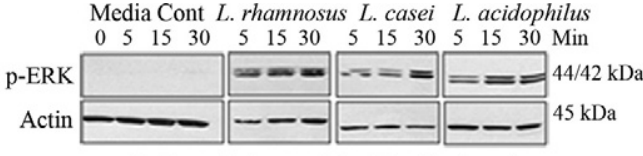

B. theta S. thermophilus E. coli S. typhimurium $\begin{array}{llllllllllllll}5 & 15 & 30 & 5 & 15 & 30 & 5 & 15 & 30 & 5 & 15 & 30 & \mathrm{Min}\end{array}$
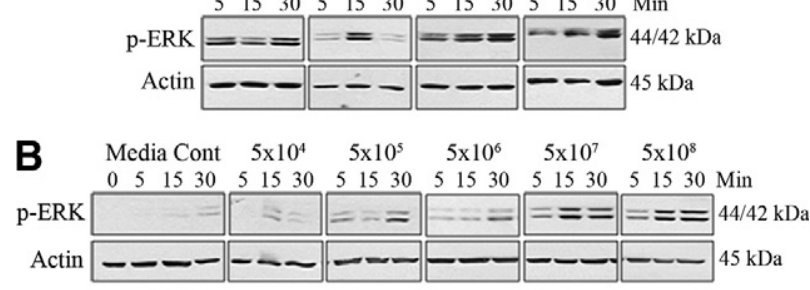

C

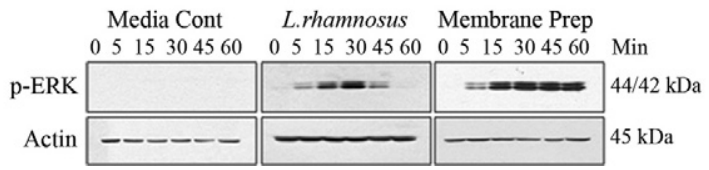

Figure 1. Apically applied enteric bacteria induce ERK phosphorylation in polarized T84 epithelial cells. All experiments were immunoblots of T84 lysates probed with a phospho-ERK specific antibody. A: Apical cell stimulation with $5 \times 10^{7} \mathrm{cfu} / \mathrm{ml}$ of Lactobacillus rhamnosus GG, Lactobacillus casei, Lactobacillus acidophilus, Bacteriodes thetaiotaomicron, Streptococcus thermophilus, Escherichia coli, or Salmonella typhimurium strains for 30 minutes. B: Apical cell stimulation with L. rhamnosus GG titered as indicated for 30 minutes. C: Apical cell stimulation with L. rhamnosus GG $5 \times 10^{7}$ $\mathrm{cfu} / \mathrm{ml}$ or L. rhamnosus GG cell wall preparation (described in methods) for 1 hour. All immunoblot experiments were repeated at least five times.

\section{Reproducibility and Data Presentation}

Differences of $P \leq 0.05$ using the Student's $t$-test were considered significant. The results of statistical analyses are given in the figure legends.

\section{Results}

\section{Enteric Bacteria Induce ERK Phosphorylation in Polarized T84 Epithelial Cells}

To investigate enteric bacterial stimulation of epithelial signaling pathways, we tested pure cultures $\left(5 \times 10^{7}\right.$ $\mathrm{cfu} / \mathrm{ml})$ of individual candidate bacteria with known commensal or pathogenic behavior. Bacteria were apically applied to polarized T84 cultured cells, incubated for up to 30 minutes, and lysates analyzed by immunoblot for MAPK or NF- $\kappa \mathrm{B}$ signaling pathway activation. For initial analysis, we assayed ERK activation, which we and others have shown is activated by both commensal and pathogenic bacteria. ${ }^{18,19}$ Each strain tested, both commensal and pathogenic, equally induced ERK phosphorylation (Figure 1A). Further studies were focused on Lactobacillus rhamnosus GG (LGG), which is used extensively as a probiotic, and has been demonstrated to affect cellular signaling processes. ${ }^{27,28}$ Apical LGG treatment robustly activated phosphorylation of ERK in a dose dependent manner with signal becoming undetectable at less than $5 \times 10^{4} \mathrm{cfu} / \mathrm{ml}$ (approximate multiplicity of infection $=0.001)($ Figure $1 B)$. ERK pathway activation was also mediated by apical contact with non-viable sonicated bacterial cell wall preparations (Figure 1C). In comparison to ERK phosphorylation mediated by live cultures of $L G G$, which show transient up-regulation over 1 hour, LGG cell wall preparation induced robust and persistent ERK activation (Figure 1C). The transient ERK activation seen with viable bacteria may be the result of active repression of signaling pathways, similar to our past observations showing commensal bacterial repressing NF- $\kappa$ B signaling. ${ }^{29}$ These data show that LGG stimulated ERK phosphorylation is not dependant on live bacteria, and that a soluble epithelial cell stimulating factor is present in the LGG membrane.

\section{L. rhamnosus GG or fMLF Specifically Activate ERK Pathway Signaling}

Bacterially stimulated ERK activation is mediated by products released by bacteria, or by determinants on the bacterial surface (Figure 1). A potential candidate bacterial product is formyl-Met-Leu-Phe tripeptide (fMLF), which is a classical activator of ERK signaling in neutrophils. ${ }^{30}$ Apically administered fMLF potently and specifically activated ERK pathway signaling, but had no stimulatory effects on the pro-apoptotic JNK, or the pro-inflammatory NF- $\kappa \mathrm{B}$ pathways in T84 cells (Figure 2, $A$ and $C$ ). Interestingly, fMLF only weakly activated ERK pathway signaling when basolaterally applied to polarized T84 cells (see supplemental Figure S1 at http:// ajp.amjpathol.org). Significantly, T84 cells apically stimulated with $5 \times 10^{7} \mathrm{cfu} / \mathrm{ml} \mathrm{LGG}$, or with LGG cell wall preparation did not activate the JNK or NF- $\kappa \mathrm{B}$ signaling pathways, whereas robust activation of these pathways occurred in control cells stimulated with TNF- $\alpha$ (Figure 2A). In addition, activation of the proliferative/survival pathway Akt was mediated by live LGG, cell wall preparations and fMLF. This data with live LGG is in striking contrast to the effects of pathogenic S. typhimurium, which activates NF- $\kappa \mathrm{B}$ and JNK signaling, in addition to ERK, consistent with past work from our laboratory (Figure 2A). ${ }^{19,29}$ Interestingly, S. typhimurium did not activate Akt in this system. To demonstrate differential signaling between myeloid and intestinal epithelial cells, murine bone marrow derived macrophages stimulated with $5 \times$ $10^{7} \mathrm{cfu} / \mathrm{ml} \mathrm{LGG}$ and $500 \mathrm{nmol} / \mathrm{L}$ fMLF over 30 minutes activated only ERK and JNK signaling pathways (Figure 2B). This is consistent with the role of macrophages as systemic immunocompetent cells, which are not in constitutive contact with bacteria as is the case with intestinal epithelial cells.

In the context of eukaryotic-prokaryotic interactions, the p38 and JNK pathways are generally considered pro-inflammatory and serve to activate innate immune responses. These MAPK classes terminate in activation of the AP-1 family of leucine zipper transcription factors (often functioning in concert with NF- $\kappa \mathrm{B}$ ) to stimulate transcription of pro-inflammatory effector genes, while the ERK MAPK pathway is preferentially activated by growth factors and other mitogenic stimuli and largely mediates proliferative and differentiation events. ${ }^{31}$ The ERK MAPK is comprised of two serine-threonine MAP kinases, ERK 1/2 (or p44MAPK and p42 MAPK) that share $83 \%$ amino acid homology and are expressed 


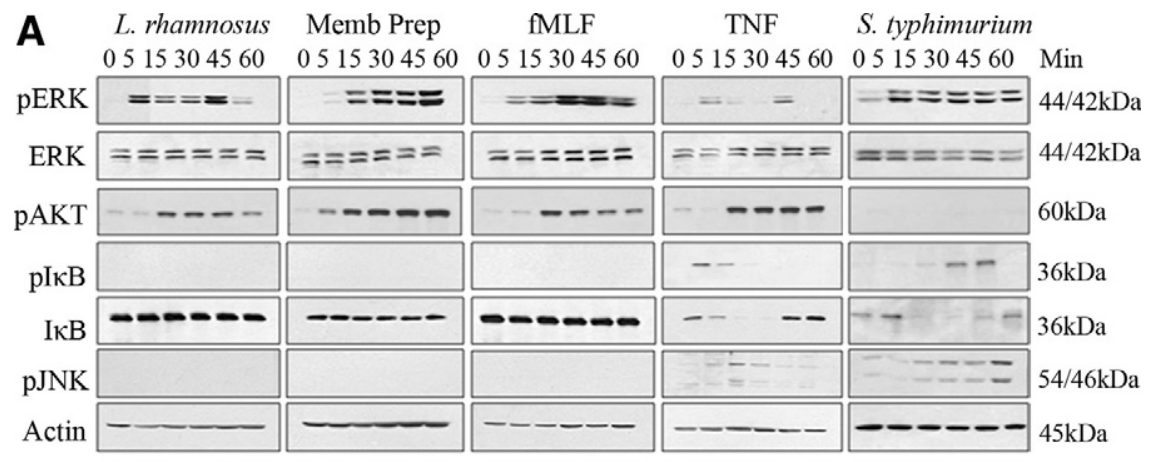

B

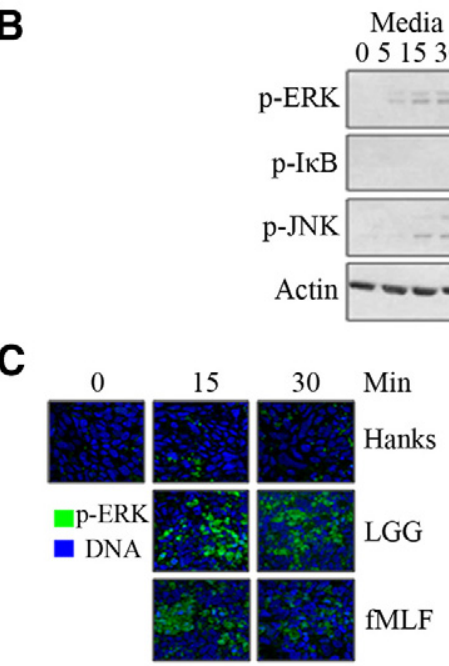

Media L. rhamnosus fMLF

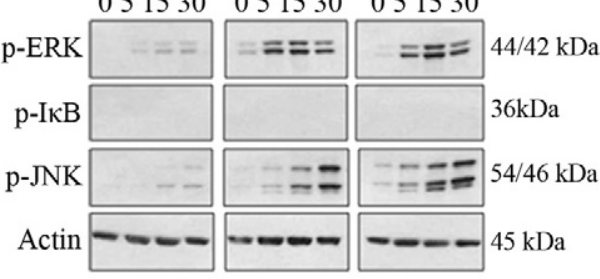

D

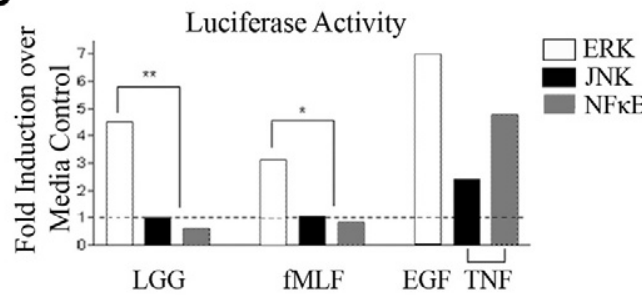

E

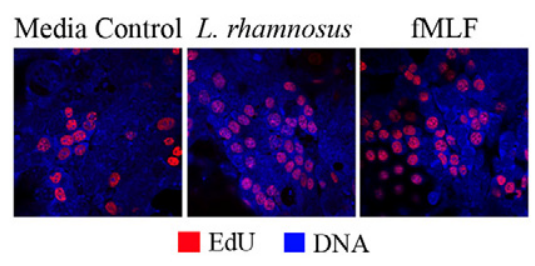

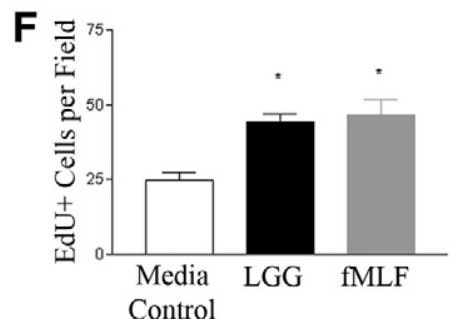

Figure 2. Apically applied L. rhamnosus GG or fMLF specifically activate ERK/Akt pathway signaling. A: Immunoblot analysis of cultured T84 cells apically stimulated with $L$. rhamnosus GG $\left[5 \times 10^{7}\right.$ $\mathrm{cfu} / \mathrm{ml}$, L. rhamnosus GG cell wall preparation fMLF $[500 \mathrm{nmol} / \mathrm{L}]$ or $S$. typhimurium $\left[1 \times 10^{8}\right.$ $\mathrm{cfu} / \mathrm{ml}]$ or basolaterally with TNF- $\alpha[10 \mathrm{ng} / \mathrm{ml}]$ for 1 hour, lysed, and probed with the indicated antibodies. B: Murine bone marrow derived macrophages stimulated with L. rhamnosus GG $[5 \times$ $\left.10^{7} \mathrm{cfu} / \mathrm{ml}\right]$ or fMLF $[500 \mathrm{nmol} / \mathrm{L}]$ over 30 minutes lysed, and probed with antibodies indicated. C: Immunofluorescence analysis of fixed T84 cultured cells apically stimulated with $L$. rhamnosus GG $\left[5 \times 10^{7} \mathrm{cfu} / \mathrm{ml}\right]$ or fMLF $[500 \mathrm{nmol} / \mathrm{L}]$ for 30 minutes. DNA (blue), Phospho-ERK (green). Confocal microscope magnification, $\times 63$. D: ERK, $\mathrm{JNK}$, or NF- $\kappa \mathrm{B}$ pathway specific luciferase reporter gene assay of transfected SK-CO15 cells treated with $L$. rhamnosus GG $\left[5 \times 10^{7} \mathrm{cfu} / \mathrm{ml}\right]$, fMLF [500 $\mathrm{nmol} / \mathrm{L}]$. EGF [200 ng/ml] or TNF- $\alpha^{16}[10 \mathrm{ng} / \mathrm{ml}$ served as activating controls for ERK and JNK/NF$\kappa \mathrm{B}$, respectively. Data are shown as fold induction over unstimulated media control. ${ }^{*} P<0.05$; ${ }^{* *} P<$ 0.001 . All immunoblot experiments repeated at least five times, and immunofluorescence experiments were repeated at least three times. For the luciferase assay, $n=6$ for each experimental treatment. E: EdU incorporation into cultured SK-CO15 cells incubated for 12 hours with L. rhamnosus GO $\left[5 \times 10^{7} \mathrm{cfu} / \mathrm{ml}\right]$ or fMLF $[500 \mathrm{nmol} / \mathrm{L}]$. DNA (blue), EdU (red). Confocal microscope magnification $\times 63$ F: Quantitative representation of EdU positive cells in (E). Number of EdU positive cells per 10 fields of view for three replicates per treatment. ${ }^{*} P<0.05$. constitutively and ubiquitously. The ERKs are largely functionally redundant, activated by a MAPKK, MEK1/2, and their substrates are vast, with over 160 potential targets described including nuclear transcription factors, cytoplasmic cytoskeletal regulators, receptors, signaling intermediates, and other kinases. ${ }^{32}$ Similarly, Akt is a key component of a signaling pathway with well-demonstrated survival and proliferative effects. ${ }^{33}$

To further examine the specificity and establish a functional measure of LGG or fMLF induced ERK pathway activation, we used transfection based ERK, JNK, and $\mathrm{NF}-\kappa \mathrm{B}$ dependent reporter assays. Elevated ERK pathway dependent luciferase activity was measured in transfected SK-CO15 cells stimulated with LGG and FMLF, whereas no JNK or NF- $\kappa$ B activity was detected in identically stimulated cells transfected with JNK or NF- $\kappa \mathrm{B}$ dependent reporter (Figure 2D). EGF or TNF- $\alpha$ serves as an activating control for $E R K$ and JNK/NF- $\kappa \mathrm{B}$, respectively. Thus, these data show that fMLF directly phenocopied LGG induced ERK pathway specific activation. Finally, to determine the extent to which LGG and fMLF induce signaling to increase cellular proliferation, we assayed for EdU incorporation. Contact of cultured epithelial cells with viable LGG and fMLF for 12 hours resulted in significant up-regulation of EdU incorporation (Figure 2, $E$ and F).

\section{Inhibition of G-Protein Coupling or Formyl Peptide Receptor Binding Attenuates LGG- or fMLF-Induced ERK Pathway Activation}

FPRs are seven transmembrane G-protein coupled receptors (GPCRs) present on the apical membrane of enterocytes. ${ }^{14}$ Because both fMLF and LGG simulate ERK pathway activation, we sought to determine whether LGG-induced ERK pathway activation is mediated via FPRs. We inhibited FPR activity using PTx, a 105-kDa exotoxin from Bordetella pertussis, which catalyzes the ADP-ribosylation of $\mathrm{G} \alpha_{\mathrm{i}}$ subunits of GPCRs and blocks downstream cellular signaling stimulated by this class of receptor. ${ }^{34}$ Polarized T84 cells were pretreated with 1 

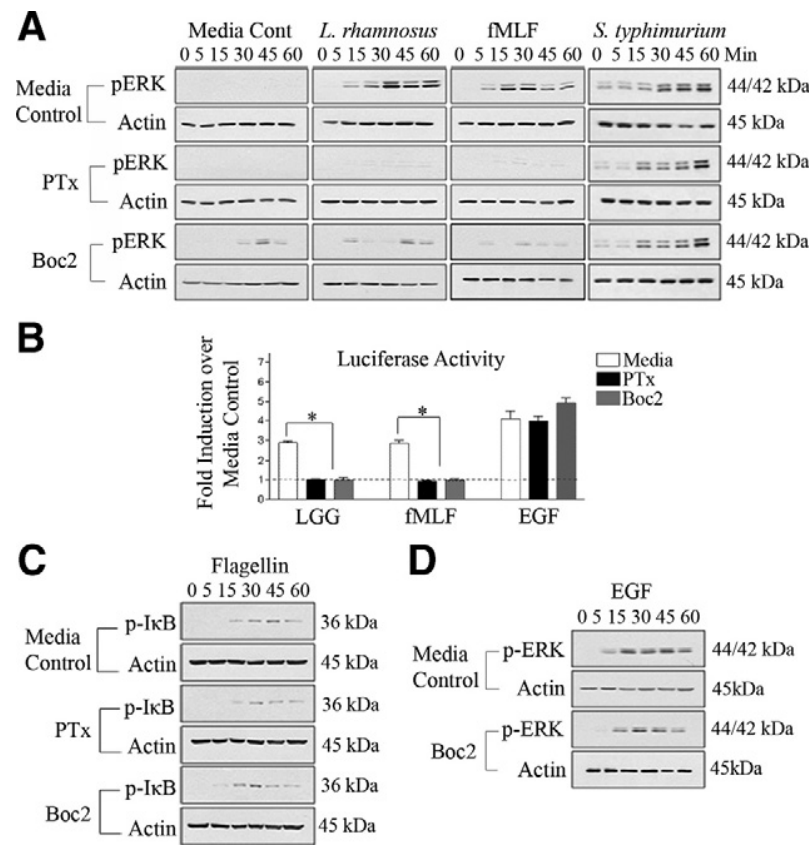

D

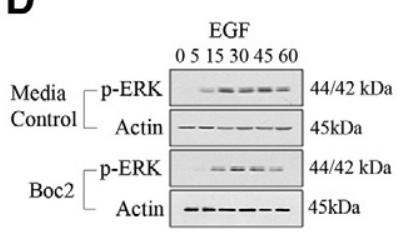

Figure 3. Inhibition of G-protein coupled receptors or formyl peptide receptors attenuates ERK phosphorylation in response to apical L. rhamnosus GG or fMLF stimulation. A: Immunoblot analysis of cultured T84 cells treated apically with PTx $[1 \mu \mathrm{g} / \mathrm{ml}]$ or Boc2 $[100 \mu \mathrm{g} / \mathrm{ml}] 30$ minutes before apical stimulation with L. rhamnosus $\mathrm{GG}\left[5 \times 10^{7} \mathrm{cfu} / \mathrm{ml}\right]$, S. typhimurium $\left[1 \times 10^{8} \mathrm{cfu} / \mathrm{ml}\right.$, or fMLF $[500 \mathrm{nmol} / \mathrm{L}]$ for 1 hour. B: ERK pathway-specific luciferase reporter gene assay from transfected SK-CO15 cells treated with either PTx $[1 \mu \mathrm{g} / \mathrm{ml}]$ or Boc2 $[100 \mu \mathrm{g} / \mathrm{ml}] 30$ minutes before L. rhamnosus GG $\left[5 \times 10^{7} \mathrm{cfu} / \mathrm{ml}\right], \mathrm{fMLF}[500 \mathrm{nmol} / \mathrm{L}]$ or EGF $[200 \mathrm{ng} / \mathrm{ml}]$ stimulation. Data are shown as fold induction over unstimulated media control. ${ }^{*} P<0.05$; ${ }^{* *} P<$ 0.001 C: Immunoblot analysis of T84 cells treated basolaterally with either PTx $[1 \mu \mathrm{g} / \mathrm{ml}$ or Boc2 [100 $\mu \mathrm{g} / \mathrm{ml}] 30$ minutes before basolateral stimulation with flagellin $[100 \mathrm{ng} / \mathrm{ml}$. D: Immunoblot analysis of T84 cells treated apically with Boc2 [100 $\mu \mathrm{g} / \mathrm{ml}] 30$ minutes before basolateral EGF $[200 \mathrm{ng} / \mathrm{ml}]$ stimulation. All experiments repeated at least three times.

$\mu \mathrm{g} / \mathrm{ml}$ PTx for 30 minutes, before apical stimulation with LGG or fMLF. PTx potently inhibited LGG- or fMLF-dependent ERK phosphorylation (Figure $3 A$ ), indicating that GPCR are required for LGG- or fMLF-dependent ERK phosphorylation.

To further functionally implicate FPR as a mediator of LGG induced ERK signaling, we used the Boc2 peptide, a fMLF peptidomimetic, which binds both FPR1 and FPR2/ALX with high affinity and has been shown to specifically block fMLF/FPR binding in neutrophils. ${ }^{16,35}$ Polarized T84 cells were incubated in the presence of Boc2 (100 ng/ml) for 30 minutes before apical treatment with LGG or fMLF (Figure 3A). Boc2 pretreatment mitigated LGG- or fMLF-induced ERK phosphorylation (Figure 3A), but importantly did not inhibit EGF-induced ERK phosphorylation (Figure 3D), a control for non-GPCR activation of ERK phosphorylation. As Boc2 is a peptidomimetic, we observed a small degree of agonist activity under media control conditions. The same analysis was performed with the invasive enteric pathogen S. typhimurium. This bacterium was able to induced ERK as shown in (Figures $1 \mathrm{~A}$ and $2 \mathrm{~A}$ ), but interestingly, this activation was not repressed by with PTx and Boc2 (Figure $3 \mathrm{~A})$, consistent with the accepted view that invasive pathogens stimulate via TLR rather than apical FPRs.
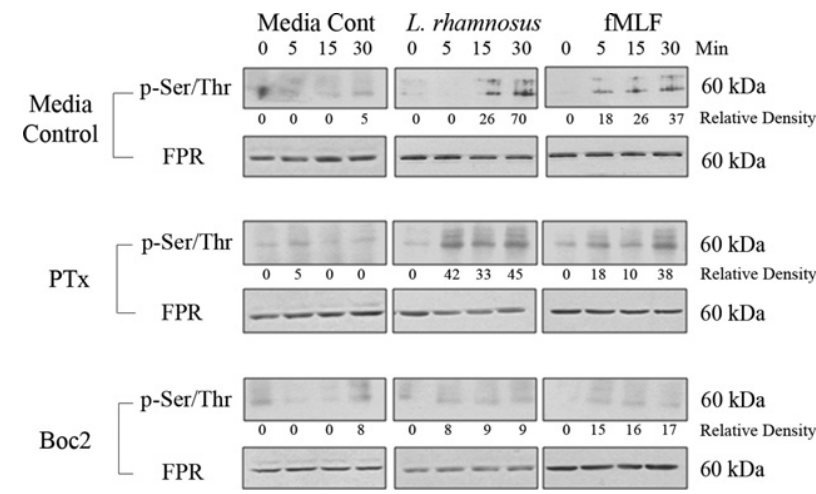

Figure 4. Apical L. rhamnosus GG and fMLF induce phosphorylation of FPR. Immunoblot analysis of immunoprecipitated FPR from cultured SK CO15 cells apically pretreated with either PTx $[1 \mu \mathrm{g} / \mathrm{ml}]$, Boc2 $[100 \mu \mathrm{g} / \mathrm{ml}]$ or Dulbecco's modified Eagle's medium 30 minutes before stimulation with $L$. rhamnosus GG $\left[5 \times 10^{7} \mathrm{cfu} / \mathrm{ml}\right]$ or fMLF $[500 \mathrm{nmol} / \mathrm{L}]$. Immunoprecipitated proteins were immunoblotted against antibodies to pSer/Thr and FPR. Immunoblot experiments repeated at least three times. Densitometric analysis normalized to background using Scion Image $\beta$.

We then investigated the inhibitory effects of PTx and Boc2 on LGG- or fMLF-induced ERK pathway activation using the previously used ERK-dependent reporter gene assay. Transfected SK-CO15 cultured cells pretreated with either PTx or Boc2 before treatment with LGG or fMLF exhibited strong attenuation of ERK pathway dependent luciferase activity (Figure 3B). Neither PTx nor Boc2 significantly decreased EGF induced ERK pathway dependent luciferase activity, confirming PTx and Boc2 specific inhibition of GPCR and FPR respectively.

To further confirm the specificity of PTx and Boc2 toward GPCR and FPR respectively, we basolaterally stimulated polarized T84 cells with flagellin, a bacterial protein known to induce NF- $\kappa$ B activation via TLR5. Neither PTx nor Boc2 treated cells inhibited flagellin induced I $\kappa$ B phosphorylation (Figure $3 \mathrm{C}$ ) demonstrating absence of PTx or Boc2 inhibitory activity toward TLR signaling.

\section{L. rhamnosus GG or fMLF Induce Phosphorylation and Activation of Formyl Peptide Receptor in Epithelial Cells}

The signaling cascade initiated by fMLF binding to FPR is mediated by phosphorylation of the receptor which, in turn, recruits the binding of accessory proteins, such as all three $\mathrm{G} \alpha_{\mathrm{i}}$ isoforms, to the second intracellular loop in the C-terminal region of FPRs. ${ }^{13}$ To experimentally demonstrate induced FPR phosphorylation (and thus activation), SK-CO15 cells were stimulated for up to 30 minutes with LGG or fMLF. Cell lysates were prepared and total FPR immunoprecipitated using an anti-FPR antibody, which recognizes both FPR1 and FPR2/ALX. ${ }^{24}$ Precipitated proteins were analyzed by immunoblot using an antibody against phosphorylated serine/threonine. Both LGG and fMLF rapidly induced the phosphorylation of FPR within 5 to 15 minutes of stimulation (Figure 4). Total amounts of FPR in the precipitated protein were analyzed using anti-FPR antibody, which detected a protein of about $60-\mathrm{kDa}$ that is invariant after agonist exposure, and 
A Media Cont Cecal Prep Supernatant

\begin{tabular}{|c|c|c|c|c|}
\hline & $\begin{array}{lllll}0 & 5 & 15 & 30 \\
\end{array}$ & $\begin{array}{llll}0 & 5 & 15 & 30\end{array}$ & $\begin{array}{lllll}0 & 5 & 15 & 30\end{array}$ & Min \\
\hline p-ERK & & $==$ & $===$ & $44 / 42 \mathrm{kDa}$ \\
\hline p-JNK & & & & $54 / 46 \mathrm{kDa}$ \\
\hline Actil & & -ー-ー & - & $45 \mathrm{kDa}$ \\
\hline
\end{tabular}
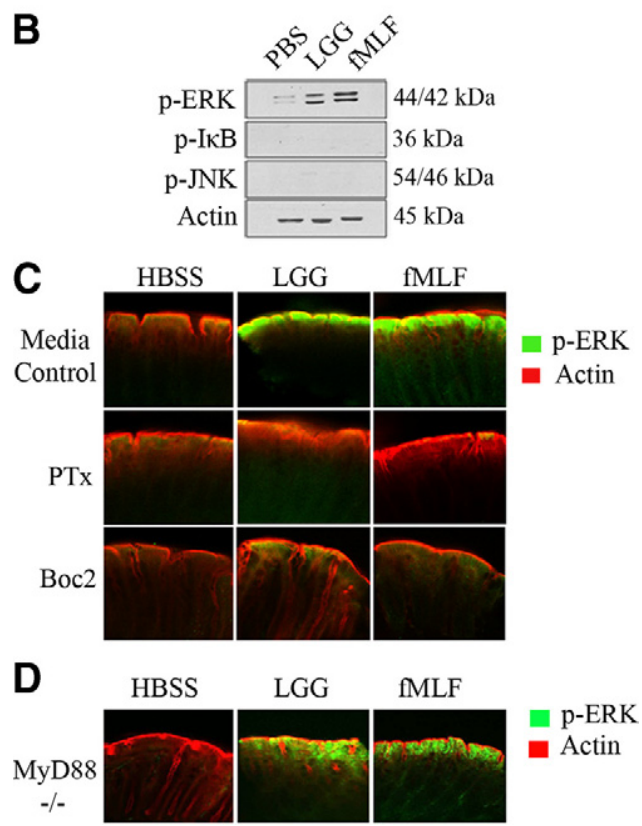

Figure 5. L. rhamnosus GG or fMLF treatment of murine colon stimulates ERK activation. A: Immunoblot analysis for phospho-ERK in T84 cells apically treated with cecal luminal preparations (as described in Materials and Methods) for 30 minutes. B: Immunoblot analysis of phospho-ERK in mouse colonic epithelial cell scrapings treated in vivo with $100 \mu \mathrm{l}$ L. rhamnosus GG $\left[1 \times 10^{7} \mathrm{cfu} / \mathrm{ml}\right]$ or $\mathrm{fMLF}[500 \mathrm{nmol} / \mathrm{L}]$ for 7 minutes. C: Immunofluorescence of phospho-ERK of intestinal whole mount preparations (as described in Material and Methods) in either baseline intestinal mucosa or pretreated in vivo with either PTx $[1 \mu \mathrm{g} / \mathrm{ml}]$ or Boc2 $[100 \mu \mathrm{g} / \mathrm{ml}] 30$ minutes before $100 \mu \mathrm{l}$ L. rhamnosus $\mathrm{GG}\left[1 \times 10^{7} \mathrm{cfu} / \mathrm{ml}\right]$ or $\mathrm{fMLF}[500 \mathrm{nmol} / \mathrm{L}]$ for 7 minutes. D: Experiment performed identically as in C on a MyD88 null background. $n \leq 3$ for each experimental murine treatment.

is consistent with the predicted molecular mass of epithelial FPR (Figure 4). Next, we examined the effect of PTx or Boc2 pretreatment before stimulation of SK-CO15 cells with LGG or fMLF. Boc2, the competitive inhibitor of extracellular fMLF binding, potently inhibited FPR phosphorylation, whereas PTx, which inhibits G protein signaling downstream of FPR activation, did not (Figure 4). Together, these data demonstrate that LGG or fMLF activate FPR in cultured epithelial cells.

\section{L. rhamnosus GG or $\mathrm{fMLF}$ Treatment of Murine Colon Stimulates ERK Activation}

We examined whether natural murine luminal contents could activate cell signaling events in vitro. Bacterial suspensions were prepared from mouse cecal contents. Supernatants from both pelleted bacteria and bacterial suspensions themselves (diluted up to eightfold) potently stimulated ERK activation in polarized T84 cells. Importantly, no up-regulation of the pro-apoptotic JNK signaling pathways were detected (Figure 5A), consistent with previous data with isolated cultures of bacteria.
To examine LGG or fMLF induced activation of ERK signaling pathway in vivo, surgically constructed murine colonic loops were instilled with $100 \mu \mathrm{l}$ LGG $\left(5 \times 10^{8}\right.$ $\mathrm{cfu} / \mathrm{ml})$ or $\mathrm{fMLF}(500 \mathrm{nmol} / \mathrm{L})$ for 7 minutes, consistent with the baseline $N$-formyl peptide content of the mammalian colon measured at $100 \mathrm{nmol} / \mathrm{L}^{36,37}$ The colon was then removed, cut longitudinally, epithelial cells scraped and lysed before immunoblot analysis. Murine intestinal epithelia incubated with LGG or fMLF show strong activation of ERK pathway signaling compared to mice treated with buffer control (Figure 5B). Again, no activation of JNK or I $\kappa \mathrm{B}$ was observed. We then administered LGG or fMLF to murine colons via direct intrarectal administration. At 7 minutes after administration, colonic sections were resected, cut longitudinally, fixed, and immunostained using antibodies against phosphorylated ERK. Both LGG and AMLF potently induced ERK pathway activation at the colonic villus tips, whereas control mice administered identical quantities of buffer did not (Figure $5 \mathrm{C}$ ). We then systemically pretreated mice with $0.5 \mu \mathrm{g} / 0.1 \mu \mathrm{l}$ PTx via intraperitoneal injection for 18 hours, ${ }^{38}$ or intrarectally pretreated $50 \mu \mathrm{g}$ Boc2 to mice for 30 minutes before intrarectal administration of LGG or fMLF for 7 minutes. Resected colonic preparations were fixed and examined for ERK pathway activation by immunofluorescence. PTx and Boc2 pretreatment resulted in markedly reduces levels of LGG or fMLF induced ERK phosphorylation in colonic villus tips compared to mice administered LGG or fMLF alone (Figure 5C). These data demonstrate the recapitulation of effects observed in polarized cultured intestinal epithelial cells in a murine model. Finally, this experiment was repeated in mice with a germ line null mutation in MyD88, an adaptor necessary for TLR2, 4, and 5 signaling. Essentially similar results were obtained (Figure 5D), indicating fMLF and LGG induced ERK signaling was not via surface TLR perception of bacteria.

\section{Discussion}

In the colon, FPRs are localized to apical villus tips, exposed to luminal contents and thus the microbiota and its products, ie, formyl peptides. ${ }^{14}$ It is important to note that most, if not all, prokaryotic translation products are formylated, thus a very wide range of bacterial protein and peptide would be expect to activate FPRs. In addition, both FPR1 and the closely related FPR2/ALX are stimulated by these ligands, albeit with different affinities. In neutrophils, sensing of formyl peptides leads to increased motility (chemotaxis), ROS generation (oxidative burst), and transcriptional response. We propose that colonic sensing of gut luminal formyl proteins and peptides likely stimulates functionally homologous outcomes. We previously showed fMLF activates phosphatidylinositol 3-kinase through Rac1 and Cdc42 and subsequent $\mathrm{Ca}+$ influx in a wound healing model, which results in activation of epithelial cytoskeletal rearrangements and cellular movement. ${ }^{14}$ Furthermore, our past work has shown that commensal bacteria ${ }^{26,39,40}$ and fMLF (unpublished data) have the ability to activate ROS in intestinal 
epithelium, although direct FPR involvement has not been confirmed.

Our data are consistent with FPR functioning as a novel PRR in the gut. Bacterial sensing by the host is generally thought to occur via leucine rich repeats bearing pattern recognition receptors such as the transmembrane TLRs and cytoplasmic Nod proteins. Our studies indicate FPRs are bona fide PRRs, though there are several unique features. One, among MAPKs, epithelial FPR signaling is limited to ERK and Akt activation and does not activate the typical pro-inflammatory MAPKs or $\mathrm{NF}-\kappa \mathrm{B}$, as we showed in macrophages (Figure 2). Additionally, FPR signaling is largely (though not solely) restricted to the apical aspect of polarized epithelia, unlike TLR signaling which occurs mainly on the basolateral surface. ${ }^{14}$ While PRR mediated signaling clearly has a central and dominant role in initiating cellular inflammation during infection, ${ }^{9,10}$ it is now also apparent that basal tonic TLR (and likely other PRR) mediated signaling in response to the microbiota and its products are necessary for mucosal health. Murine models with defective PRR signaling are hypersensitive to a variety of intestinal insults and stressors, and supplementation of TLR ligands such as CpG DNA and flagellin can have cytoprotective effects. ${ }^{41,42}$ This has led to the hypothesis that a constitutive degree of PRR signaling is necessary for normal gut homeostasis and underscores the importance of gut-prokaryotic interaction as a beneficial and necessary relationship. ERK activation is known to stimulate proproliferative gene regulatory events and initiate cytoskeletal rearrangements necessary for epithelial movement, ${ }^{31,32}$ though it is not typically considered pro-inflammatory and would not be expected to mediate overt innate immune responses in intestinal epithelial cells. As the normal microbiota (and therapeutic probiotic administration) is associated with epithelial growth and wound healing, FPR mediated activation of ERK signaling may represent a novel pathway, parallel to the TLR/Nod mediated pathways, by which microbial signals are transduced to affect epithelial physiology. This notion is consistent with observations where small peptides derived from $\mathrm{H}$. pylori signal via FPRs in vitro and can accelerate mucosal gastric injury in vivo. ${ }^{43}$ Furthermore, the FPR related receptor GPR43 has recently been identified as a receptor for short chain fatty acids - a product of the intestinal microbiota - and has a clear role in the resolution of intestinal inflammation. ${ }^{44}$ Indeed, FPR2ALX was originally characterized by its antiinflammatory and pro-resolving actions, where germline mutations resulted in enhanced inflammation in a variety of models. ${ }^{45}$ Thus, the presence of these receptors on gut epithelia, and exposed to an environment highly enriched in bacteria and their products suggest therapeutic stimulation of the FPRs may be relevant to treating intestinal inflammation/injury.

\section{Acknowledgments}

We thank Ruth Napier for excellent technical advice.

\section{References}

1. Gill SR, Pop M, Deboy RT, Eckburg PB, Turnbaugh PJ, Samuel BS, Gordon JI, Relman DA, Fraser-Liggett CM, Nelson KE: Metagenomic analysis of the human distal gut microbiome. Science 2006, 312:1355-1359

2. Xu J, Mahowald MA, Ley RE, Lozupone CA, Hamady M, Martens EC Henrissat B, Coutinho PM, Minx P, Latreille P, Cordum H, Van Brunt A, Kim K, Fulton RS, Fulton LA, Clifton SW, Wilson RK, Knight RD, Gordon Jl: Evolution of symbiotic bacteria in the distal human intestine. PLoS Biol 2007, 5:e156

3. Hooper LV, Bry L, Falk PG, Gordon JI: Host-microbial symbiosis in the mammalian intestine: exploring an internal ecosystem. Bioessays 1998, 20:336-343

4. Neish AS: Microbes in gastrointestinal health and disease. Gastroenterology 2009, 136:65-80

5. Hooper LV, Gordon JI: Commensal host-bacterial relationships in the gut. Science 2001, 292:1115-1118

6. Pull SL, Doherty JM, Mills JC, Gordon JI, Stappenbeck TS: Activated macrophages are an adaptive element of the colonic epithelial progenitor niche necessary for regenerative responses to injury. Proc Natl Acad Sci USA 2005, 102:99-104

7. Park J, Floch MH: Prebiotics, probiotics, and dietary fiber in gastrointestinal disease. Gastroenterol Clin N Amer, Nutr Gastrointest IIIness 2007, 36:47-63

8. Sartor RB: Microbial influences in inflammatory bowel diseases. Gastroenterology 2008, 134:577-594

9. Ishii KJ, Koyama S, Nakagawa A, Coban C, Akira S: Host innate immune receptors and beyond: making sense of microbial infections. Cell Host Microbe 2008, 3:352-363

10. Medzhitov R: Recognition of microorganisms and activation of the immune response. Nature 2007, 449:819-826

11. Migeotte I, Communi D, Parmentier M: Formyl peptide receptors: a promiscuous subfamily of $G$ protein-coupled receptors controlling immune responses. Cytokine Growth Factor Rev 2006, 17:501-519

12. Rabiet MJ, Huet E, Boulay F: The N-formyl peptide receptors and the anaphylatoxin C5a receptors: an overview. Biochimie 2007, 89:1089-1106

13. Ye RD, Boulay F, Wang JM, Dahlgren C, Gerard C, Parmentier M, Serhan CN, Murphy PM, International Union of Basic and Clinical Pharmacology, LXXIII: Nomenclature for the formyl peptide receptor (FPR) family. Pharmacol Rev 2009, 61:119-161

14. Babbin BA, Jesaitis AJ, Ivanov Al, Kelly D, Laukoetter M, Nava P, Parkos CA, Nusrat A: Formyl peptide receptor-1 activation enhances intestinal epithelial cell restitution through phosphatidylinositol 3-kinase-dependent activation of Rac1 and Cdc42. J Immunol 2007, 179:8112-8121

15. Serhan CN, Chiang N, Van Dyke TE: Resolving inflammation: dual anti-inflammatory and pro-resolution lipid mediators. Nat Rev Immunol 2008, 8:349-361

16. Babbin BA, Lee WY, Parkos CA, Winfree LM, Akyildiz A, Perretti M, Nusrat A: Annexin I regulates SKCO-15 cell invasion by signaling through formyl peptide receptors. J Biol Chem 2006, 281:19588-19599

17. Canny G, Levy O, Furuta GT, Narravula-Alipati S, Sisson RB, Serhan CN, Colgan SP: Lipid mediator-induced expression of bactericidal/ permeability-increasing protein (BPI) in human mucosal epithelia. Proc Natl Acad Sci USA 2002, 99:3902-3907

18. Chang L, Karin M: Mammalian MAP kinase signalling cascades. Nature 2001, 410:37-40

19. Zeng H, Carlson AQ, Guo Y, Yu Y, Collier-Hyams LS, Madara JL, Gewirtz AT, Neish AS: Flagellin is the major proinflammatory determinant of enteropathogenic Salmonella. J Immunol 2003, 171:3668-3674

20. Hooper LV, Wong MH, Thelin A, Hansson L, Falk PG, Gordon JI: Molecular analysis of commensal host-microbial relationships in the intestine. Science 2001, 291:881-884

21. Madara JL, Stafford J, Dharmsathaphorn K, Carlson S: Structura analysis of a human intestinal epithelial cell line. Gastroenterology 1987, 92:1133-1145

22. Kim HJ, Zhao H, Kitaura H, Bhattacharyya S, Brewer JA, Muglia LJ, Ross FP, Teitelbaum SL: Glucocorticoids suppress bone formation via the osteoclast. J Clin Invest 2006, 116:2152-2160

23. Collier-Hyams LS, Sloane V, Batten BC, Neish AS: Cutting edge: 
bacterial modulation of epithelial signaling via changes in neddylation of cullin-1. J Immunol 2005, 175:4194-4198

24. Riesselman M, Miettinen HM, Gripentrog JM, Lord Cl, Mumey B, Dratz EA, Stie J, Taylor RM, Jesaitis AJ: C-terminal tail phosphorylation of $\mathrm{N}$-formyl peptide receptor: differential recognition of two neutrophil chemoattractant receptors by monoclonal antibodies NFPR1 and NFPR2. J Immunol 2007, 179:2520-2531

25. Collier-Hyams LS, Zeng H, Sun J, Tomlinson AD, Bao ZQ, Chen $H$ Madara JL, Orth K, Neish AS: Cutting edge: salmonella AvrA effector inhibits the key proinflammatory, anti-apoptotic NF-kappa B pathway. $J$ Immunol 2002, 169:2846-2850

26. Kumar A, Wu H, Collier-Hyams LS, Hansen JM, Li T, Yamoah K, Pan ZQ, Jones DP, Neish AS: Commensal bacteria modulate cullin-dependent signaling via generation of reactive oxygen species. EMBO J 2007, 26:4457-4466

27. Resta-Lenert S, Barrett KE: Probiotics and commensals reverse TNF[alpha]- and IFN-[gamma]-induced dysfunction in human intestinal epithelial cells. Gastroenterology 2006, 130:731-746

28. Yan F, Cao H, Cover TL, Whitehead R, Washington MK, Polk DB: Soluble proteins produced by probiotic bacteria regulate intestinal epithelial cell survival and growth. Gastroenterology 2007, 132:562-575

29. Neish AS, Gewirtz AT, Zeng H, Young AN, Hobert ME, Karmali V, Rao AS, Madara JL: Prokaryotic regulation of epithelial responses by inhibition of IkappaB-alpha ubiquitination. Science 2000, 289:1560-1563

30. Torres M, Hall FL, O'Neill K: Stimulation of human neutrophils with formyl-methionyl-leucyl-phenylalanine induces tyrosine phosphorylation and activation of two distinct mitogen-activated protein-kinases. J Immunol 1993, 150:1563-1577

31. Johnson GL, Lapadat R: Mitogen-activated protein kinase pathways mediated by ERK. JNK, and p38 protein kinases. Science 2002, 298:1911-1912

32. Roux PP, Blenis J: ERK and p38 MAPK-activated protein kinases: a family of protein kinases with diverse biological functions. Microbiol Mol Biol Rev 2004, 68:320-344

33. He XC, Yin T, Grindley JC, Tian Q, Sato T, Tao WA, Dirisina R, Porter-Westpfahl KS, Hembree M, Johnson T, Wiedemann LM, Barrett TA, Hood L, Wu H, Li L: PTEN-deficient intestinal stem cells initiate intestinal polyposis. Nat Genet 2007, 39:189-198

34. Bokoch GM, Gilman AG: Inhibition of receptor-mediated release of arachidonic acid by pertussis toxin. Cell 1984, 39:301-308

35. Gavins FN, Yona S, Kamal AM, Flower RJ, Perretti M: Leukocyte antiadhesive actions of annexin 1: aLXR- and FPR-related anti-inflammatory mechanisms. Blood 2003, 101:4140-4147
36. Chadwick VS, Mellor DM, Myers DB, Selden AC, Keshavarzian A, Broom MF, Hobson $\mathrm{CH}$ : Production of peptides inducing chemotaxis and lysosomal enzyme release in human neutrophils by intestinal bacteria in vitro and in vivo. Scand J Gastroenterol 1988, 23:121-128

37. Marasco WA, Phan SH, Krutzsch H, Showell HJ, Feltner DE, Nairn R, Becker EL, Ward PA: Purification and identification of formyl-methionyl-leucyl-phenylalanine as the major peptide neutrophil chemotactic factor produced by Escherichia coli. J Biol Chem 1984 259:5430-5439

38. Hou W, Wu Y, Sun S, Shi M, Sun Y, Yang C, Pei G, Gu Y, Zhong C, Sun B: Pertussis toxin enhances Th1 responses by stimulation of dendritic cells. J Immunol 2003, 170:1728-1736

39. Kumar A, Wu H, Collier-Hyams LS, Kwon YM, Hanson JM, Neish AS: The bacterial fermentation product butyrate influences epithelial signaling via reactive oxygen species-mediated changes in cullin-1 neddylation. J Immunol 2009, 182:538-546

40. Lin PW, Myers LE, Ray L, Song SC, Nasr TR, Berardinelli AJ, Kundu K, Murthy N, Hansen JM, Neish AS: Lactobacillus rhamnosus blocks inflammatory signaling in vivo via reactive oxygen species generation. Free Radic Biol Med. 2009, 47:1205-1211

41. Lee J, Mo JH, Katakura K, Alkalay I, Rucker AN, Liu YT, Lee HK, Shen C, Cojocaru G, Shenouda S, Kagnoff M, Eckmann L, Ben-Neriah Y, Raz E: Maintenance of colonic homeostasis by distinctive apical TLR9 signalling in intestinal epithelial cells. Nat Cell Biol 2006 8:1327-1336

42. Rakoff-Nahoum S, Paglino J, Eslami-Varzaneh F, Edberg S, Medzhitov $\mathrm{R}$ : Recognition of commensal microflora by toll-like receptors is required for intestinal homeostasis. Cell 2004, 118:229-241

43. de Paulis A, Prevete N, Rossi FW, Rivellese F, Salerno F, Delfino G Liccardo B, Avilla E, Montuori N, Mascolo M, Staibano S, Melillo RM, D'Argenio G, Ricci V, Romano M, Marone G: Helicobacter pylori $\mathrm{Hp}(2-20)$ promotes migration and proliferation of gastric epithelial cells by interacting with formyl peptide receptors in vitro and accelerates gastric mucosal healing in vivo. J Immunol 2009, 183:3761-3769

44. Maslowski KM, Vieira AT, Ng A, Kranich J, Sierro F, Yu D, Schilter HC, Rolph MS, Mackay F, Artis D, Xavier RJ, Teixeira MM, Mackay CR: Regulation of inflammatory responses by gut microbiota and chemoattractant receptor GPR43. Nature 2009, 461:1282-1286

45. Dufton N, Hannon R, Brancaleone V, Dalli J, Patel HB, Gray M, D'Acquisto F, Buckingham JC, Perretti M, Flower RJ: Anti-inflammatory role of the murine formyl-peptide receptor 2: ligand-specific effects on leukocyte responses and experimental inflammation. J Immunol 2010, 184:2611-2619 